\title{
Ethos discursivo e subjetividade no jornalismo: William Bonner em tempos eleitorais
}

\author{
Discursive ethos and the subjectivity in journalism: William Bonner in election times \\ Ethos discursivo y subjetividad en el periodismo: William Bonner en tiempos electorales \\ Iverton Gessé Ribeiro Gonçalves (1) \\ Universidade de Passo Fundo, Passo Fundo, RS, Brasil.
}

$\diamond$

\begin{abstract}
RESUMO
O presente artigo estuda o discurso de William Bonner em tempos eleitorais, no intento de analisar a subjetividade (BENVENISTE, 1995a, 1995b), a cenografia e o ethos discursivo (MAINGUENEAU, 2004, 2008a, 2008b, 2008c) constituintes das entrevistas realizadas por esse jornalista aos candidatos à presidência da república em 2014. Como corpus, selecionamos recortes de três entrevistas realizadas pelo Jornal Nacional aos presidenciáveis. Os procedimentos metodológicos que guiam esse estudo são de abordagem qualitativa e método descritivo e bibliográfico. Busca-se analisar as marcas deixadas no discurso como parte intrínseca da imagem do enunciador do Jornal Nacional. O estudo da cenografia permite vislumbrar o ethos discursivo de alguém que se impõe como incontestável, conhecedor de todos os discursos e que, ancorado no gênero entrevista, se sente na obrigação de polemizar todos os enunciados alheios. Um indivíduo justiceiro é o que se pode depreender da imagem que Bonner lança de si no discurso.
\end{abstract}

Palavras-chave: Cenografia. Ethos discursivo. Subjetividade. Jornalismo. William Bonner.

\begin{abstract}
This study starts of the discourse of William Bonner in election times, aims to analysis the subjectivity (BENVENISTE, 1995a, 1995b), the scenography and the discursive ethos (MAINGUENEAU, 2004, 2008a, 2008b, 2008c) present in the interviews realized y Bonner to candidates for president this year. We selected sections of tree interviews did by Jornal Nacional as corpus this study. The methodological procedures are qualitative and descriptive and bibliographic method. We seek to analyze the brands left in speech as image of enunciator that interviews the candidates in Jornal Nacional. The study of scenography allows to identify the discursive ethos of someone who imposes as incontestable, expert of all discourses and, ensured by interview's gender, feels obliged to argue all others statements. A justice person is the image himself that Bonner casts in discourse.
\end{abstract}

Keywords: Scenography. Discursive Ethos. Subjectivity. Journalism. William Bonner.

\section{RESUMEN}

El presente artigo estudia el discurso de William Bonner en tiempos electorales, para analizar la subjetividad (BENVENISTE, 1995a, 1995b), la escenografía e el ethos discursivo (MAINGUENEAU, 2004, 2008a, 2008b, 2008c) constituyentes de las entrevistas realizadas por este periodista a los candidatos a la presidencia de la república en 2014. El corpus es compuesto por recortes de tres entrevistas realizadas por el telediario Jornal Nacional a los presidenciables. Los procedimientos metodológicos de esto estudio son de abordaje cualitativo y método descriptivo y bibliográfico. Intenta-se analizar las marcas que quedan en el discurso como parte intrínseca de la imagen del enunciador del Jornal Nacional. El estudio de la escenografía permite identificar el ethos discursivo de alguien que se impone como incontestable, conocedor de todos los discursos y que, por el género entrevista, se siente en la obligación de polemizar todos los enunciados ajenos. Un individuo juzgador es lo que se puede deprender de la imagen que Bonner alza de si en el discurso.

Palabras clave: Escenografía. Ethos discursivo. Subjetividad. Periodismo. William Bonner. 


\section{Introdução}

O presente trabalho se propõe a analisar o comportamento enunciativo de William Bonner no campo de sua atuação profissional, o jornalismo, a fim de compreender as marcas de subjetividade deixadas em seus enunciados e o ethos discursivo que daí se apreende. No processo de campanha eleitoral de 2014, os presidenciáveis estiveram frente a frente ao âncora do Jornal Nacional, da Rede Globo e, durante os seus embates, cada um dos candidatos foi intimado a conceder à pessoa de William Bonner a posição de locutor-sujeito ${ }^{1}$, resignando-se à posição de alocutário. Isso posto, a temática escolhida se justifica pelo interesse em analisar e compreender a movimentação enunciativa desse indivíduo que se propõe como pessoa na cena da enunciação e instaura um tu em âmbito nacional, nosso interesse almeja contribuir para com os estudos enunciativo-discursivos que se pautam no fio da subjetividade e/ou na instauração do ethos discursivo.

A pesquisa realizada para esse estudo suscita a seguinte questão norteadora: os enunciados de William Bonner, durante as entrevistas realizadas aos presidenciáveis no processo eleitoral de 2014, apresentadas no Jornal Nacional, nos permitem estudar a subjetividade no processo enunciativo relacionando-a a construção do ethos discursivo desse jornalista. Atrelado à questão norteadora, nosso objetivo consiste em analisar as marcas de subjetividade e descrever o ethos discursivo de Bonner enquanto sujeito da enunciação nas entrevistas aos presidenciáveis.

A fundamentação teórica que baliza nosso estudo concentra-se nas postulações de Benveniste (1995a, 1995b) quanto à subjetividade na linguagem e à implicação de demais instâncias do discurso no processo enunciativo. Maingueneau (2004, 2008a, 2008b, 2008c) completa nosso embasamento teórico com os estudos enunciativo-discursivos que delineiam as categorias teóricas de cenografia enunciativa e de ethos discursivo.

O corpus desse estudo é constituído por três vídeos disponível na página do G1/Jornal Nacional e compõem a série de entrevistas realizadas com os candidatos à presidência da república, no pleito de 2014. Os procedimentos metodológicos norteadores da análise qualificam a abordagem como qualitativa, descritiva quanto aos objetivos do estudo, e bibliográfica e documental no que diz respeito aos procedimentos técnicos. Analisamos o discurso de Bonner partindo da dupla relação teórica

\footnotetext{
1 Usamos, apenas na seção introdutória, a dupla categoria locutor-sujeito sob o viés da teoria benvenisteana, embora para Benveniste (1995) essas instâncias do discurso não são sinônimas; cada uma delas corresponde a categoria de pessoa em diferentes etapas do processo enunciativo. Explicitaremos essa distinção ao longo do trabalho respeitando o que o autor nos propõe.
}

(Benveniste - Maingueneau), considerando não só o fato de o locutor se propor como sujeito, como também a forma como esse enunciador, sujeito, se lança sobre o seu coenunciador, o seu $t u$. Ainda sobre o enunciador, daremos atenção à imagem que constrói de si e do outro e os inúmeros elementos que invoca para a construção de uma cenografia que lhe permita enunciar-se e legitimar-se pela própria enunciação.

A estrutura do trabalho compreende, primeiramente, o percurso teórico sobre a Enunciação, postulações de Benveniste (1995a, 1995b). A revisão teórica avança sob a abordagem de Maingueneau (2004, 2008a, 2008b, 2008c). Posteriormente, são detalhados os procedimentos metodológicos, seguidos da constituição do corpus desse trabalho. Na sequência, configura-se a análise do corpus. E, por fim, as considerações finais.

\section{Subjetividade: a metamorfose do locutor em sujeito}

Falar de subjetividade em Benveniste (1995a) é aceitar o laço embrionário que liga o homem à linguagem. Isto é, compreender o homem que se constitui na e pela linguagem. Nunca separado dela, nunca inventor dela. A existência do homem não pode ser concebida fora da linguagem. E, assim como constitui a si mesmo na linguagem, constitui também a outro homem. "A linguagem ensina a própria definição do homem" (BENVENISTE, 1995a, p. 285). Na linguagem é instaurada a condição de pessoa ou, nas palavras do teórico, "É um 'ego' que diz ego". É nessa afirmação que reside a concepção enunciativa de pessoa, sendo essa uma das afirmativas benvenisteanas mais relevantes para entendermos o fundamento da subjetividade.

$\mathrm{O}$ fato de o homem se constituir na e pela linguagem comporta duas relações, uma antropológica e outra própria de língua. Na primeira concepção, o homem se constitui na linguagem porque é somente no uso da língua, na realidade da linguagem que ele pode se afirmar sujeito. A linguagem é o lugar de existência do homem, fora dela há apenas um ser biológico. Já na segunda abordagem, o homem se constitui pela linguagem porque é por esse viés que ele se propõe como sujeito, é a linguagem que o possibilita de registrar a sua existência. Vemos então que a subjetividade se assinala pela "capacidade do locutor [de se] propor como "sujeito"'. Essa perspectiva permite compreender o que significa: "É um 'ego' que diz ego".

A princípio, nos parece uma repetição de termos que não se explicam, no entanto, no decorrer de seus estudos, Benveniste não deixa dúvidas. "[...] eu designa o locutor que este se enuncia como "sujeito" (BENVENISTE, 1995a, p. 288). Em seus estudos sobre Benveniste, Flores (2013, p. 100, grifo do autor) corrobora essa possível 
leitura dizendo que "os dois usos de 'ego' não podem ser tomados como sinônimos" e propõe uma paráfrase que elucidaria o fundamento linguístico de subjetividade: "é sujeito quem diz "eu". O sujeito assume o uso desse fundamento linguístico. Mas esse sujeito não provém simplesmente da linguagem, ele é fruto de um locutor. Como vimos, o locutor propõe-se como sujeito. $\mathrm{O}$ eu, referindo-se ao "ato do discurso no qual é pronunciado" (BENVENISTE, 1995a, p. 288) é designado pelo locutor.

O pensamento de Benveniste (1995a) deixa claro que o ato de se apropriar da língua é próprio do locutor, portanto, não se pode pensar que é o sujeito quem se apropria da língua. O sujeito é a forma como o locutor se apresenta na língua. A passagem que ocorre de locutor a sujeito pela apropriação da língua é o cerne da subjetividade. Vemos, portanto, que a apropriação da língua faz do locutor um sujeito que fala e consequentemente o demarca linguisticamente com o status de pessoa.

De acordo com Benveniste (1995a, p.289) a emergência da subjetividade é possibilitada pelo fato de a língua possuir formas vazias que podem ser adequadas à expressividade de quem intenciona delas fazer uso. O locutor, apropriando-se dessas formas que fazem referência à sua "pessoa", se inscreve no discurso definindo-se como "eu" e delegando ao seu parceiro a definição de "tu". Assim temos: "[...] eu, que pode ser assumido por todo locutor, com a condição de que ele, cada vez, só remeta à instância do seu próprio discurso. Esse signo está, pois, ligado ao exercício da linguagem [...]" (BENVENISTE, 1995a, p. 281, grifo do autor).

Ao explicitar as formas vazias definidas pelo exercício da língua, Benveniste (1995a, p.281) formula duas concepções de linguagem: "a linguagem como sistema de signos e a linguagem assumida como exercício pelo indivíduo". Logo, ao ser passível de apropriação, a linguagem é atualizada tornando-se, doravante, instância do discurso.

A dupla definição de linguagem para Benveniste é importante, pois nos permite entender a língua como "repertório de signos" e, portanto como o eixo paradigmático de possibilidades da língua para o locutor; e também possibilita compreender a língua como "sistema das suas combinações", isto é, como eixo sintagmático no qual o sujeito faz as combinações linguísticas que estruturarão o seu discurso. No primeiro processo ocorre a apropriação da língua e no segundo, os termos dos quais o sujeito se apropria são atualizados nas combinações sintagmáticas. A junção dessa dupla atividade para o ato de enunciar-se inscreve a língua como "atividades manifestadas nas instâncias de discurso caracterizadas como tais por índices próprios" (BENVENISTE, 1995a, p. 283). Eis a concepção de "língua-discurso".
A categoria de tempo também é diretamente afetada pela categoria de pessoa, pois, sendo a existência do sujeito unicamente do universo da língua, o acontecimento linguístico é atualizado para o presente do sujeito que o instaura, isso é, para o presente do interior do discurso (BENVENISTE, 1995a, p. 289). O autor ainda afirma que "Toda forma verbal, sem exceção, em qualquer idioma que seja, está sempre ligada a um certo presente, portanto a um conjunto cada vez único de circunstâncias [...]" (BENVENISTE, 1995a, p. 230).

Podemos perceber que Benveniste entende todos os envolvidos no processo enunciativo como únicos inéditos - em cada processo específico, a citar, o tempo, a língua, o sujeito e até mesmo o espaço (que não explicitaremos aqui). Fiorin (2004, p. 16) dá autenticidade ao que entendemos sobre enunciação em Benveniste, quando diz que a enunciação "é a instância que povoa o enunciado de pessoas, de tempo e de espaços".

Flores (2013, p. 109, grifo do autor) reforça a interpretação de que o presente benvenisteano é conexo à categoria de pessoa. Os dois, juntos, constituem "o eixo organizador da presença da dialética singular". O passado e o futuro são descritos, em Problemas de Linguística Geral II (1995b, p. 76), como "visões sobre o tempo, projetadas para trás e para frente, a partir do ponto presente", considerando o presente como o ato enunciativo do locutor.

A seção seguinte aborda a concepção de cenografia e de ethos discursivo, na perspectiva enunciativo-discursiva proposta por Maingueneau (2002, 2008a, 2008b).

\section{Cenografia e ethos discursivo: a busca pela legitimação}

Entendemos que a enunciação, em uma perspectiva linguística, se configura por um conjunto de marcas de um enunciado, enquanto em uma concepção discursiva os enunciados são frutos de uma dimensão sócio-histórica. Segundo Amossy (2008), a análise pragmática se funda na ideia de troca. A análise enfatiza a maneira como o locutor se comporta na interlocução para construir uma imagem de si. E o ethos discursivo, portanto, só é constituído a partir dos participantes e do cenário.

A concepção de enunciação, em uma perspectiva enunciativo-discursiva, é entendida como o ato de produzir enunciados, enquanto o enunciado se configura como a marca verbal produzida na enunciação, isto é, um "produto da enunciação que implica uma cena" (MAINGUENEAU, 2002, p.96). Conforme Maingueneau (2002, p.56), falar se confirma como uma ação, e não apenas uma representação, pois a fala intenciona modificar uma situação. Na busca por adesão à mudança, todo discurso institui a cena de enunciação que 
o legitima. A fala necessita validar-se progressivamente na própria enunciação. Isso nos coloca diante de um enlaçamento paradoxal em que a cenografia construída deve ser "a fonte do discurso e aquilo que a engendra" (MAINGUENEAU, 2002, p. 87).

Nesse particular, falar em discurso implica em interatividade entre dois enunciadores, isto é, $e u$ e $t u$, que operarão sobre a enunciação em função das atitudes do outro e percebendo as reações imediatas do outro, como já expusemos em Amossy (2013). A competência comunicativa intrínseca a esse processo não está firmada apenas na competência enciclopédica e/ou linguística, pois para que o coenunciador interprete um enunciado, é preciso que ele reconstrua os seus sentidos partindo das indicações presentes na enunciação, a começar pelo gênero, isto é, a começar pela desenvoltura da competência genérica. Mais que isso, cabe falarmos em competência discursiva que, além de produzir e interpretar enunciados, corresponde ao fato de o enunciador adequar-se às regras de seu posicionamento discursivo.

A competência discursiva, de acordo com Facin (2012, p.44), pode ser entendida como a subjetividade benvenisteana, pois exige uma seleção, por parte do sujeito, de determinados textos dentro de uma formação discursiva específica. Indo mais além, a competência em um espaço discursivo ampliado, passa a ser interdiscursiva, uma vez que exige do indivíduo reconhecer os enunciados que correspondem a sua formação discursiva e perceber a incompatibilidade de enunciados de seu Outro (MAINGUENEAU, 2008a, p. 55).

Cada situação de enunciação constrói o seu próprio discurso e, conjuntamente, cada discurso constrói um quadro cênico para legitimar o seu dizer. Sobre o enunciador desse discurso cria-se a expectativa de que ele se apresente como fiador, servindo como fonte legítima do que está sendo enunciado. O enunciador é tido como aquele que é dotado de autoridade para se enunciar e, portanto, o que autoriza aquele discurso. Todo ato enunciativo necessita de um enunciador encarnado, Maingueneau (2008c) o conceitualiza como ethos discursivo. $O$ enunciador se reveste de algumas características para que a enunciação seja aceitável ou não (MAINGUENEAU, 2002, p. 98).

O enunciador assume uma corporalidade e um caráter conforme um conjunto de representações sociais variadas, valorizadas ou não, sobre as quais se sustenta a enunciação. O caráter (traços psicológicos) e a corporalidade (compleição corporal e a maneira de se movimentar no espaço) possibilitam a apreensão global do ethos discursivo.

De acordo com Maingueneau (2002, p. 99) a "maneira de dizer [...] remete a uma maneira de ser". O universo de sentido oportunizado no discurso é assegurado pelo ethos e pelas ideias que transmite, daí a relevância do ethos na enunciação assimétrica. Por fim, mas não menos importante, o autor afirma que "o ethos deve estar afinado com a conjuntura ideológica" (MAINGUENEAU, 2002, p. 100).

Assim, concebe-se, para a análise do discurso na perspectiva enunciativo-discursiva, o ethos como "parte constitutiva da cena da enunciação". Quanto à terminologia, no que concerne a análise do discurso, ethos discursivo assume o sentido de uma construção da "imagem de si por meio do discurso" (FREITAS, 2010, p. 179, grifo do autor).

Maingueneau (2008c) configura a classificação de ethos duas facetas: ethos pré-discursivo e ethos discursivo. Como ethos pré-discursivo, importa a caracterização prévia do enunciador por parte do coenunciador, pois serve como avalista na expectativa em matéria de ethos. Ainda que o coenunciador não tenha conhecimento sobre o caráter do enunciador, ele pode prevê-lo pelo gênero do discurso em que o enunciador se inscreve ou mesmo pelo posicionamento ideológico que salta das expectativas desse ethos (MAINGUENEAU, 2008b).

No entanto, o ethos não é identificado no imediatismo da enunciação. Há que se ter em mente que "ao mesmo tempo que o enunciador constrói o seu ethos para validar o seu discurso, é o próprio discurso que também valida e dá corpo ao enunciador. É como um processo em espiral"(FACIN, 2012, p. 55).

Maingueneau (2008b) formaliza, no que se refere ao ethos, o termo tom como toda a vocalidade do discurso, seja esse oral ou escrito. O tom que possibilita a vocalidade garante perceber a identidade de um determinado posicionamento discursivo. Nesse sentido, o discurso é tomado como um acontecimento que se inscreve em uma configuração sócio-histórica e não pode sofrer uma dissociação entre os seus conteúdos e o modo com que a sua cena discursiva se constrói para legitimá-lo.

Maingueneau (2008b) confere ao ethos discursivo duas vias de composição: o ethos mostrado e o ethos dito. O ethos mostrado é o que o enunciador deixa transparecer de si pela enunciação (seu comportamento enunciativo) e dessa deixa se vai formalizando a instalação do ethos; já o ethos dito é aquilo que o enunciador evoca como forma de construir-se em seu discurso, as referências diretas que faz de si. Corrobora nosso entendimento sobre ethos, os estudos de Serena (2013, p.62), sobre Maingueneau, quando descreve que: "[...] ao falar de si mesmo, o sujeito deixa evidente algo sobre seu caráter, sua imagem e sua identidade". No entanto, se o discurso apresenta índices linguísticos que revelam uma imagem não dita, então, estamos diante de um ethos mostrado.

Vale lembrar que "A distinção entre ethos dito e ethos mostrado inscreve-se nos extremos de uma linha 
contínua, já que é impossível definir uma fronteira clara entre o 'dito sugerido' e o 'mostrado' não explícito" (MAINGUENEAU, 2008b, p. 82, grifo do autor). Embora pareça simples a delimitação desses termos, enfatizamos que definir a fronteira entre eles é uma tarefa bastante complexa. A construção, ou instalação, do ethos em seus diferentes vieses pode ser observada na Figura 1:

Figura 1 - Ethos discursivo

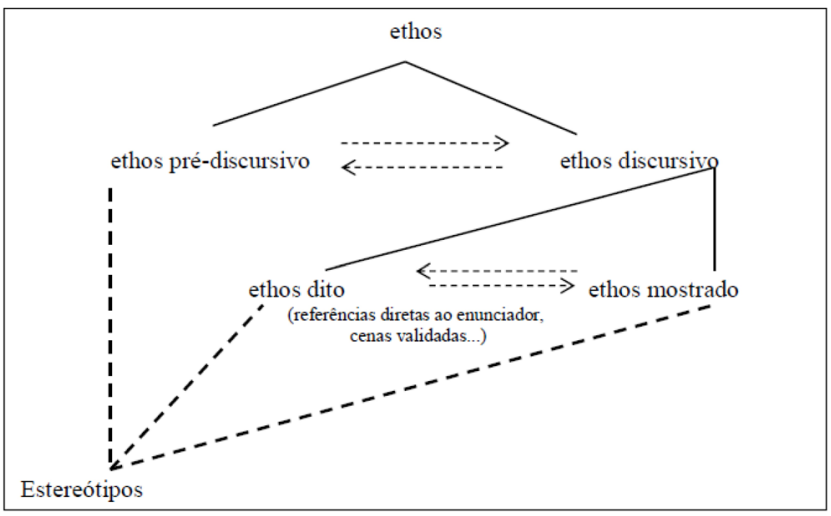

Fonte: Maingueneau (2008b, p. 83).

É impossível falar de ethos sem trazer para a discussão a noção de cena enunciativa, uma vez que a constituição da imagem do enunciador depende da desenvoltura e da legitimação da cena da enunciação. É inegável a relação da cenografia com a construção do ethos, uma vez que a cenografia se constrói para legitimar o que é dito pelo enunciador, ao mesmo tempo em que legitima o próprio enunciador mediante o ethos que ele instala, esperando dele uma recíproca legitimadora.

Aperspectiva enunciativo-discursiva propõe olharmos para a cena da enunciação em um desdobramento de três planos enunciativos: a cena englobante, a cena genérica e a cenografia (MAINGUENEAU, 2002). A cena englobante corresponde ao tipo de discurso, que pode ser amplamente identificado como: religioso, político, publicitário, filosófico, científico etc. Vislumbrar essa cena nos oportuniza identificar os possíveis posicionamentos para determinados campos discursivos. Além disso, aceitamos a necessidade de conceber um discurso por intermédios dos gêneros discursivos e, portanto, por intermédio das cenas genéricas, segundo desdobramento da cena da enunciação (MAINGUENEAU, 2002). O terceiro nível é o que mais nos permite acesso às idiossincrasias da cena enunciativa, pois o discurso permite a construção de um quadro cênico, isto é, a construção de seu próprio dispositivo de fala. $\mathrm{O}$ autor entende que "uma cenografia só se manifesta plenamente se puder controlar o próprio desenvolvimento, manter a distância em relação ao coenunciador" (MAINGUENEAU, 2002, p. 88).
Quanto ao quadro cênico e à cenografia, Freitas (2011, não paginado) explicita que a enunciação "leva o quadro cênico (cena englobante e cena genérica) a se deslocar para um segundo plano, pois quando um texto apresenta uma cenografia, é por meio dela que esse texto se 'mostra' ou se 'dá a conhecer' a seu coenunciador"'. Essa citação entra em consonância com a afirmação de Maingueneau (2008b) quando afirma que há alguns gêneros que não fornecem espaço para suscitar cenografias, são gêneros que se resignam a uma cena genérica padronizada, como por exemplo, o despacho administrativo e os relatórios técnicos, entre outros.

Maingueneau (2008b) ainda pondera sobre a incidência do ethos sobre as cenas de fala já instaladas na memória coletiva e as designa como cenas validadas. As cenas validadas estão paradoxalmente estabelecidas no interior e no exterior do discurso. Concebendo que essas cenas já existem em algum lugar no interdiscurso, elas preexistem ao discurso que as evoca. Mas também, são interiores, pois se configuram de acordo com o universo próprio do discurso para o qual são evocadas.

Por fim, Maingueneau (2002) formaliza a cenografia como um processo de enlaçamento paradoxal, pois é gerada no discurso e deve legitimar o discurso que a gerou. É necessário conceber que a cena que é construída para determinada fala é exatamente a cena requerida para legitimar aquela enunciação. Serena (2013, p.58) em uma paráfrase de inegável inteligibilidade afirma que cenografia compreende uma noção de teatralidade e grafia, isto é, "a obra se legitima criando um enlaçamento, propiciando ao leitor um mundo cujo caráter exige que a própria cenografia represente aquilo que diz".

A seção seguinte é dedicada à delimitação dos procedimentos metodológicos e à análise prevista.

\section{Metodologia e análise do corpus}

Após revisitarmos cada uma das teorias convocadas para essa pesquisa, nos vemos na complexa, porém frutífera, tarefa de estabelecer uma interface entre a subjetividade na linguagem e a constituição do ethos discursivo. Sabemos que cada uma das abordagens apresenta peculiaridades, no entanto, concebemos a possibilidade de lidar com essas nuances a partir de uma visada cooperativa em que cada uma das teorias colabore com o seu modo de olhar sobre o corpus desse trabalho.

Além das peculiaridades que se postulam como desafios, destacamos a mutação de termos e conceituações que ocorrem de uma para outra perspectiva teórica. Para sanarmos esse problema, estabelecemos o compromisso de, ao evocarmos termos específicos, vinculá-los ao autor ou à teoria que os postula. 


\section{Procedimentos metodológicos}

O estudo que intentamos realizar se caracteriza como descritivo-qualitativo e bibliográfico tendo como corpus alguns recortes das entrevistas realizadas no Jornal Nacional, na Rede Globo, durante o período eleitoral de 2014 para a presidência da república. Os recortes dão preferência para os momentos em que William Bonner se enuncia. As entrevistas estão publicadas, em formato de vídeo, na página do G1/Jornal Nacional, conforme constam nas Referências deste trabalho. Optamos por selecionar trechos das entrevistas que Bonner realizou com os candidatos Aécio Neves, Dilma Roussef e Marina Silva. A análise do corpus está traçada a partir dos seguintes procedimentos metodológicos:

a) Partiremos da apreciação dos vídeos e posterior transcrição para a língua escrita, de maneira que tenhamos condições de registrar os enunciados que nos interessam para a análise;

b) no momento seguinte, buscaremos identificar marcas de subjetividade nos enunciados construídos durante as entrevistas e a posição que o locutor delega ao seu alocutário;

c) em um terceiro momento, verificaremos a imagem do enunciador dentro da cenografia que constrói, verificando também os aspectos que constituem a própria cenografia;

d) de acordo com as peculiaridades constituídas em cada uma das entrevistas, analisaremos a imagem de si que o locutor constrói no discurso, depreendendo um ethos específico das cenas enunciativas.

O espaço a seguir é dedicado à análise do corpus.

\section{O sujeito que diz "boa noite": análise do ethos discursivo de William Bonner}

William Bonner, nas entrevistas aos candidatos à presidência da república durante a campanha eleitoral de 2014, constrói um corpo enunciativo que será analisado doravante.

\section{ENTREVISTA 1 - Aécio Neves}

O Jornal Nacional abre hoje a série de entrevistas, ao vivo, com os principais candidatos à Presidência da República. Nós vamos abordar os temas polêmicos das candidaturas e também confrontar os candidatos com o seu desempenho em cargos públicos. Nas próximas semanas, os candidatos estarão também no Bom Dia Brasil e no Jornal da Globo.

William Bonner: Candidato, quando o senhor critica a situação da economia brasileira, o senhor tem dito que, seja quem for o presidente eleito para o ano que vem, vai ter que fazer uma arrumação da casa. O senhor já mencionou choque de gestão, redução de número de ministérios, redução de cargos comissionados. O senhor já falou em combate a desperdícios. Mas economistas que concordam com o seu diagnóstico para a economia brasileira dizem que essas medidas que o senhor tem anunciado não bastam, elas não seriam suficientes para resolver. Que seria necessário que o governo fizesse um corte profundo de gastos. Que seria necessário que o governo também eliminasse a defasagem de tarifas públicas como preço da gasolina e energia elétrica. A questão é a seguinte: o senhor não vai fazer essas medidas que os economistas defendem? Ou o senhor está procurando não mencionar essas medidas, por que elas são impopulares? William Bonner: Mas o senhor não respondeu a minha pergunta. A minha pergunta é se entre essas necessidades se inclui a redução dos gastos públicos e o fim dessa defasagem das tarifas de energia e gasolina.

William Bonner: Mas o senhor vai aumentar as tarifas?

William Bonner: A minha pergunta é sobre usar um aeroporto que foi construído pelo estado de Minas Gerais para visitar uma fazenda sua. Isso não lhe constrange?

\section{ENTREVISTA 2 - Dilma Roussef}

E é por isso que estamos aqui em Brasília, no Palácio do Alvorada, porque é aqui que nós fazemos as entrevistas com presidentes candidatos à reeleição.

William Bonner: Candidata, no seu governo houve uma série de escândalos de corrupção e de desvios éticos. Houve escândalo de corrupção no Ministério da Agricultura, houve escândalo de corrupção no Ministério das Cidades, no Ministério dos Esportes, houve escândalo de corrupção no Ministério da Saúde, no Ministério dos Transportes, houve escândalo de corrupção no Ministério do Turismo, no Ministério do Trabalho. A Petrobras acabou se tornando objeto de duas CPIs no Congresso. A senhora sempre diz que todos esses escândalos foram revelados pela Polícia Federal e estão sendo investigados pela Polícia Federal, que é um órgão do governo federal. A questão que eu lhe faço é a seguinte: qual é a dificuldade de, desde o início, se cercar de pessoas honestas, que lhe permitam formar uma equipe de governo honesta e que evite esta situação que nós vimos de repetidos casos de corrupção? Não há uma sensação, não pode haver uma sensação no ar de que o PT descuida da questão ética ou da questão da corrupção? William Bonner: Correto. Mas, candidata, eu deveria só dizer à senhora o seguinte: a senhora listou aqui uma série de medidas que foram providenciadas depois de ocorridos os escândalos.

William Bonner: Então, me deixa agora perguntar à senhora. E em relação a seu partido? O seu partido teve 
um grupo de elite de pessoas corruptas, comprovadamente corruptas, eu digo isso porque foram julgadas, condenadas e mandadas para a prisão pela mais alta corte do Judiciário brasileiro. Eram corruptos. E o seu partido tratou esses condenados por corrupção como guerreiros, como vítimas, como pessoas que não mereciam esse tratamento, vítimas de injustiça. A pergunta que eu lhe faço: isso não é ser condescendente com a corrupção, candidata?

William Bonner: Então a senhora condena a postura do PT nesse caso?

William Bonner: Mas e a ação do seu partido, a senhora condena essa ação?

William Bonner: Mas o resultado, no momento, é muito ruim, candidata.

William Bonner: Inflação alta, indústrias com estoques elevados, ameaça de desemprego ali na frente.

William Bonner: Da indústria, candidata.

William Bonner: Isso não é ser otimista em contrapartida ao pessimismo que a senhora critica?

William Bonner: Candidata, nosso tempo...

William Bonner: Eu que agradeço a sua presença no Jornal Nacional.

\section{Entrevista 3 - Marina Silva}

William Bonner: Candidata, o avião que o PSB vinha utilizando na campanha eleitoral, até aquele acidente trágico de duas semanas atrás, está sendo investigado pelas autoridades competentes. Ele foi objeto de uma transação milionária feita por meio de laranjas. Essa transação não foi informada na prestação de contas prévia, parcial, à Justiça Eleitoral. A senhora tem dito que vai inaugurar uma nova forma de fazer política, que todo político tem que ter certeza absoluta da correção de seus atos. No entanto, a senhora usou aquele avião como teria feito qualquer representante daquilo que a senhora chama de velha política. Eu lhe pergunto: a senhora procurou saber que avião era aquele, quem tinha pago por aquele avião, ou a senhora confiou cegamente nos seus aliados?

William Bonner: A senhora sabia dos laranjas? Essa informação foi passada para a senhora como candidata a vice-presidente?

William Bonner: Candidata, quando os políticos são confrontados ou cobrados por alguma irregularidade, é muito comum que eles digam que não sabiam, que foram enganados, que foram traídos, que tudo tem que ser investigado, que se houver culpados, eles sejam punidos. Este é um discurso muito, muito comum aqui no Brasil. E é o discurso que a senhora está usando neste momento. Eu lhe pergunto: em que esse seu comportamento difere do comportamento que a senhora combate tanto da tal velha política?

William Bonner: Agora, é que a senhora tem uma postura bem rigorosa no que diz respeito à ética, no discurso, quando a senhora se dirige aos seus adversários. Esse rigor ético que a senhora exige dos seus adversários nos faz perguntar e insistir se a senhora antes de voar naquele avião não teria então deixado de fazer a pergunta obrigatória se estava tudo em ordem em relação àquele voo. Não lhe faltou o rigor que a senhora exige dos seus adversários?

William Bonner: Candidata...

William Bonner: Não, não. Estou confrontando apenas com posições que a senhora tem assumido sobre a nova política em oposição à velha política. E não está clara para mim a diferença quando a gente vê dois candidatos de posições opostas unidos numa chapa. Era só essa a questão.

A seguir, focamos nossa análise nas instâncias do discurso que fundamentam a subjetividade. Conjuntamente, analisaremos de que forma a cenografia engendra e é engendrada nesse discurso.

Como podemos observar na Entrevista 1, o locutor que se apropria do aparelho formal para enunciar-se no espaço da entrevista não institui diretamente o candidato presente como seu $t u$ (BENVENISTE, 1995a). O indivíduo alocutário aqui é o telespectador que, por necessidade de ser contextualizado, recebe informações do que está acontecendo. Ao enunciar-se, Bonner já, como afirma Fiorin (2004), povoou o enunciado de pessoas, tempo e espaços. Vemos assim, de imediato, que a linguagem, usada para situar o telespectador, é a que garante a existência de cada uma das instâncias do discurso. O candidato é localizado na terceira pessoa, o que para Benveniste (1995a, p. 251) é uma não pessoa. “"A terceira pessoa' não é uma 'pessoa'; é inclusive a forma verbal que tem por função exprimir a não-pessoa"'. O tempo presente hoje é atualizado para o presente da enunciação e o espaço criado é o espaço discursivo construído pelo discurso que possibilita a realização da entrevista. Ao informar seu $t u$-telespectador sobre a entrevista, já se tem uma organização do discurso, por parte do sujeito que indica quem será o seu próximo alocutário. A forma verbal nós não inclui o telespectador nem o candidato, essa forma é uma ampliação do $e u$ que se enuncia juntamente a todos os eus que fazem o Jornal Nacional acontecer.

Conforme vimos em Benveniste (1995a) as formas vazias da língua possibilitam a subjetividade porque podem ser adequadas à expressividade de quem lança mão delas para enunciar-se. Nitidamente se percebe o ser da palavra como detentor de todo o poder do discurso, pois é ele quem se apropria da língua, instaura uma relação de intersubjetividade ora com o telespectador, ora com o candidato. Podemos evidenciar também, além do nós, algumas formas vazias que criam sentido no 
processo enunciativo, como, por exemplo, nas seguintes passagens: "Nas próximas semanas / A minha pergunta é / porque é aqui que nós fazemos as entrevistas / candidata, eu deveria só dizer à senhora./ Não está claro pra você, mas eu vou deixar claro para o telespectador". As formas vazias acima não conseguem se respaldar em nenhum significado se tomadas fora da enunciação. É, pois, no discurso em que essas formas são atualizadas e são combinadas com as demais formas para o processo de semantização. Tanto as formas de tempo, (próximas semanas) quanto de espaço (aqui) e pessoa (minha, nós, $e u$, você) só podem ser definidas se tivermos acesso ao todo da enunciação.

A subjetividade, conforme Teixeira (2012,p.66), é "constituída pela intersubjetividade". É com a atenção voltada para a intersubjetividade que chegamos à abordagem de Maingueneau sobre a cenografia: "uma cenografia só se manifesta plenamente se puder controlar o próprio desenvolvimento, manter a distância em relação ao coenunciador" (MAINGUENEAU, 2002, p. 88). Assim, entendemos que, ao delimitar os coenunciadores como candidatos, já se denota a construção de uma cenografia, por parte de um enunciador, cuja intenção é manter a distância de seus coenunciadores.

Após esclarecer como será a organização em cada uma das entrevistas, William Bonner instaura Aécio Neves, Dilma Roussef e Marina Silva como seu $t u$, interpelando-os como candidato. Destaca-se que o jornalista, ao tratar seu $t u$ de candidato, demarca uma escolha paradigmática que não é ingênua. A entrevista é voltada para o público eleitor e para a oportunidade de campanha, portanto, Aécio, Dilma e Marina não poderiam ser constituídos no discurso fazendo referência aos demais papéis sociais que ocupam. No discurso de Bonner eles são construídos como candidatos, nada mais. $\mathrm{O}$ homem não só constitui a si na linguagem como constitui também ao outro, isso porque "A linguagem ensina a própria definição do homem” (BENVENISTE, 1995a, p.285).

Ao iniciar o processo enunciativo em todas as entrevistas, o sujeito faz a escolha das formas verbais: temas polêmicos e confrontar, deixando esclarecido que relação pretende estabelecer com o indivíduo alocutado. Em seguida, para dar conta de formalizar o que sinalizou, William retoma enunciados anteriores de Aécio. "[...] $o$ senhor tem dito. O senhor já mencionou [...]." De Dilma. "[...] A senhora sempre diz que [...]." E de Marina. "[...] A senhora tem dito que vai [...]" para com eles garantir a polemicidade. Entendemos que por mais que esses enunciados tenham sido construídos em um tempo anterior à enunciação em análise, todas as formas possíveis de se registrarem no enunciado são atualizadas pelo sujeito, conforme propõe Benveniste (1995a, p. 289). Essas formas são escolhidas pelo sujeito e essa escolha é própria da subjetividade, pois precisa garantir a realização da intenção a que se propôs. A intenção de polêmica é fomentada pela retomada - atualização - de enunciados anteriores à enunciação temporânea.

Para chegarmos ao plano da cenografia, retomamos o que Freitas (2011, não paginado) nos expõe, afirmando que "A enunciação leva o quadro cênico (cena englobante e cena genérica) a se deslocar para um segundo plano". É dessa forma que entendemos o discurso de Bonner. A enunciação carrega tanto a cena englobante (discurso político) quanto a cena genérica (entrevista) para um plano cenográfico construído pelo discurso e do qual necessita para legitimar o seu discurso.

A cena genérica que aqui é usada para conceber o discurso é deslocada para uma cenografia de tribunal, uma encenação de fala inquisitorial. As perguntas que são direcionadas aos candidatos não são simplesmente para dar a eles a oportunidade de expor as suas propostas de governo. São perguntas inquisidoras. Perguntas que atacam não só as suas vidas públicas como também pessoais. Vejamos: "Usar um aeroporto que foi construido pelo estado de Minas Gerais para visitar uma fazenda sua [Aécio]. Isso não lhe constrange?" / "Isso não é ser condescendente com a corrupção, candidata [Dilma]?" / "Em que esse seu comportamento difere do comportamento que a senhora [Marina] combate tanto da tal velha política?"

William cumpre aqui um de seus propósitos estabelecidos no início das entrevistas. "Nós vamos abordar os temas polêmicos das candidaturas e também confrontar os candidatos com o seu desempenho em cargos públicos". A cenografia que ele cria é apenas para legitimar seu dizer. Maingueneau (2002, p. 87) é dogmático quando entende que "a cenografia é, assim, ao mesmo tempo, aquela de onde o discurso vem e aquela que ele engendra". O entrevistador se propõe a polemizar, confrontar, averiguar desempenhos e cumpre, ao longo da cena de enunciação, com o seu compromisso inicial. Mais que um tribunal, Bonner se coloca em uma postura de pai de família. A cenografia que se cria, além da bancada inquiridora do jornal, é a prestação de contas dentro de casa. Isso se comprova quando o enunciador retoma um enunciado anterior de Aécio. "Quem for o presidente eleito para o ano que vem, vai ter que fazer uma arrumação da casa". É essa arrumação na casa que Bonner intenciona realizar assistido pela grande família brasileira. Da bancada de Jornal, que não é nem local, nem regional, é nacional, Bonner pretende desbancar cada um dos candidatos. Expõe um a um ao confessionário nacional, deixando à mostra as fragilidades de seus coenunciadores, a falibilidade de seus projetos e a incapacidade de gestão.

A cena englobante que depreendemos do nosso corpus pode ser caracterizada como parte do discurso 
político. Quanto à cena genérica, o próprio enunciador a implanta como entrevista que, poderíamos adjetivá-la como televisiva e político-jornalística. Dessa cena genérica espera-se que cada um dos coenunciadores se comporte conforme propõe o gênero em questão. Bonner estabelece algumas regras que organizarão a cena enunciativa e, ao tomar essa atitude, dá uma imagem de si, a de detentor e organizador da palavra. Maingueneau (2008b) ressalta o fato de alguns gêneros não fornecerem espaço para suscitar cenografias, esses gêneros são totalmente estruturados em uma cena genérica padronizada. No corpus que selecionamos há uma padronização estrutural inicial que é quebrada, uma vez que, tanto Bonner quanto os demais, não estão absolvidos de legitimar o seu dizer e, portanto, precisam investir na construção de cenografias legitimadoras.

Destacamos uma das estratégias de Bonner para expor os seus parceiros na enunciação. Quando retoma as perguntas já feitas sinaliza para o telespectador à incapacidade do coenunciador de compreender e responder coerentemente às indagações:

William Bonner: Mas o senhor não respondeu a minha pergunta. A minha pergunta é se entre essas necessidades se inclui a redução dos gastos públicos e o fim dessa defasagem das tarifas de energia e gasolina? (Entrevista 1 - Aécio Neves).

William Bonner: Então a senhora condena a postura do PT nesse caso?

William Bonner: Mas e a ação do seu partido, a senhora condena essa ação? (Entrevista 2 - Dilma Roussef).

William Bonner: Não, não. Estou confrontando apenas com posições que a senhora tem assumido sobre a nova política em oposição à velha política. E não está clara para mim a diferença quando a gente vê dois candidatos de posições opostas unidos numa chapa. Era só essa a questão (Entrevista 3 - Marina Silva).

Evidenciamos ainda, como um forte indício da natureza contestadora do enunciador-Bonner, a excessiva recorrência a construções sintáticas adversativas, em que discorda do coenunciador, como se pode ver: Mas economistas que concordam [...] Mas o senhor não respondeu [...] Mas o senhor vai aumentar as tarifas? [...] Mas, candidata, eu deveria só dizer à senhora o seguinte:[...] Mas e a ação do seu partido, a senhora condena essa ação? [...] Mas o resultado, no momento, é muito ruim, candidata. [...] No entanto, a senhora usou aquele avião.

Da constituição progressiva de uma cenografia perquiridora, podemos depreender os principais traços da subjetividade do locutor que, não constrói ingenuamente seu discurso. Todas as formas selecionadas e combinadas dão conta de uma atuação de autoritarismo e irrepreensibilidade. Resulta-nos um ethos discursivo de justiceiro e defensor da população, que se coloca à disposição dos eleitores para fazer perguntas que muitos gostariam de fazer, mas não têm oportunidade.

Nesse ponto, apreendemos a formulação benvenisteana sobre linguagem (BENVENISTE, 1995a), quando diz que a língua pode ser tomada como um sistema de signos e pode ser assumida como exercício pelo indivíduo. Bonner, ao apropriar-se da língua, atualiza-a. Assim, o locutor que toma a palavra nas entrevistas, faz a sua passagem a sujeito e se enuncia. Por fim, pelas seleções paradigmáticas e combinações sintagmáticas que realiza (repetições de perguntas, recorrência excessiva ao uso de conectores adversativos etc.) é possível defini-lo como indivíduo em seu propósito semantizador.

O ethos discursivo se constrói como sendo a voz do povo e, para rebater os argumentos apresentados pelos candidatos, esse ethos recorre a vozes que o autorizam a questionar as atitudes dos candidatos. "[...] economistas que concordam com o seu diagnóstico para a economia brasileira dizem que essas medidas que o senhor tem anunciado não bastam, elas não seriam suficientes para resolver. / [...] eu digo isso porque foram julgadas, condenadas e mandadas para a prisão pela mais alta corte do Judiciário brasileiro. / [...] Essa transação não foi informada na prestação de contas prévia, parcial, à Justiça Eleitoral”. Reforçando-se nas vozes de autoridade, o enunciador legitima-se no discurso, constitui-se como a pessoa mais indicada a indagar os candidatos, visto que tem conhecimento sobre inúmeros fatos e apresenta boa desenvoltura nos demais campos discursivos. Nesse particular, Facin (2012, p. 55) pondera sobre a necessidade de o enunciador construir um ethos para validar o seu discurso ao mesmo tempo em que o discurso confere corpo ao enunciador e o valida.

Algumas vezes, Bonner assume a postura de desentendimento. O ethos dito constitui-se como um indivíduo que não compreende os fatos (enquanto o ethos mostrado segue em direção oposta) apenas como uma armadilha para que o coenunciador retome o que já registrou em seus enunciados. "[...] não está clara para mim a diferença [...] Não há uma sensação, não pode haver uma sensação no ar de que o PT descuida da questão ética ou da questão da corrupção?" Outras vezes dá uma apreensão diferente daquilo que foi enunciado e lança uma conclusão difusa para cima de seus parceiros na enunciação. Comprovamos na seguinte passagem "[...] qual é a dificuldade de, desde o início, se cercar de pessoas honestas [...]", em que Bonner pressupõe que a candidata tenha enfrentado dificuldade para encontrar 
pessoas honestas. As referências linguísticas denotam que o enunciador desconhece as dificuldade de se cercar de pessoas honestas, dando a sugestão de um ethos dito desinformado, mas a movimentação enunciativa do ethos mostrado leva para o caminho de confrontação, cuja finalidade é deixar claro para o interlocutor que ele está cercado de pessoas desonestas.

Por fim, o incontestável, o defensor de todas as classes sociais, o pai que não aceita nada errado em sua casa, expõe para toda a população, as vísceras daqueles que ousam contestar a sua palavra. Deixa demarcado em seu discurso que tudo, dali da sua bancada, está patente a seus olhos. Como bom pai e juiz irrepreensível, disciplina os rebeldes e desenterra os cadáveres que seus enunciadores enterraram no lamaçal da política, para com eles assombrar os desavisados presidenciáveis. Demarca o seu ethos como o único que detém a verdade, o único que realmente auxilia a população a viver diariamente. E que qualquer que ouse se propagar pelo País sem passar pelo seu crivo, merece ser punido. A sua palavra é incontestável. Fiorin (2004) nos diz que o sujeito povoa o discurso. O caminho inverso também ocorre, pois o locutor, sendo o que se apropria da linguagem e dá ao alocutário o direito de existir dentro do discurso, tem todo o poder de despovoar o discurso e fulminar com a existência do $t u$. Bonner é o que permite aos demais existirem em sua janela televisiva, mas não por muito tempo, pois ele, como pai, precisa garantir a sua posição intocável no centro das atenções da família brasileira. A sua palavra é sempre a última, a sua palavra é criadora, ou fulminante: "Candidata, nosso tempo...".

\section{Considerações finais}

Iniciamos nosso percurso teórico a partir da subjetividade na linguagem (BENVENISTE, 1995a, 1995b), através da passagem de locutor a sujeito, além de abordarmos o processo de enunciação balizado pelo repertório paradigmático e pelas combinações sintagmáticas. Em seguida, discorremos sobre a imagem que o enunciador constrói de si no discurso, a relação que estabelece com seu coenunciador e o quadro cênico com sua segmentação em cena englobante, cena genérica e cenografia (MAINGUENEAU, 2004, 2008a, 2008b, 2008c).

Relacionar os dispositivos teóricos de duas diferentes perspectivas nos ratificou a eficiência que essas abordagens podem apresentar se postas em diálogo, e, consequentemente, nos permitiu alcançar o objetivo de pesquisa: analisar as entrevistas de William Bonner aos presidenciáveis, investigando as marcas de subjetividade deixadas em seus enunciados, chegando, por meio da cenografia, à apreensão o ethos discursivo que é construído nesse discurso.
O ethos que conseguimos vislumbrar a partir do corpus analisado apresenta características provocadoras. Entendemos o ethos de Bonner em tempos eleitorais como uma figura paterna, justiceira e intransigentemente defensora. As categorias teóricas acionadas dão conta de fazer-nos compreender e apreender a luta de forças que ocorre na sociedade por meio da linguagem, principalmente em tempos eleitorais. Como vimos em Benveniste, a linguagem serve para viver, sem ela é impossível conceber sociedade, humanidade.

Por fim, concebemos esse trabalho como uma modesta contribuição aos estudos que são desenvolvidos no campo da enunciação benvenisteana, bem como às pesquisas realizadas sob o farol da teoria enunciativodiscursiva. Cremos na necessidade de aprimorá-lo e de explorá-lo em outros aspectos, para os quais não pudemos dar atenção no momento.

\section{Referências}

AMOSSY, Ruth. O ethos na intersecção das disciplinas: retórica, pragmática, sociologia dos campos. In: AMOSSY, Ruth (org.). Imagens de si no discurso: a construção do ethos. Tradução Dilson Ferreira da Cruz, Fabiana Komesu, Sírio Possenti. São Paulo: Contexto, 2008, p. 119-144. https://doi. org/10.26512/les.v10i2.9291

BENVENISTE, E. Problemas de Linguística Geral I. São Paulo: Pontes, 1995a.

BENVENISTE, E. Problemas de Linguística Geral II. São Paulo: Pontes, 1995b.

FACIN, D. O enlaçamento enunciativo de um ritual carnavalizado: cenografia e ethos discursivo em sambasenredo de escolas carnavalescas do meio-oeste catarinense. 2012. 119 p. Dissertação (Mestrado em Letras) Universidade de Passo Fundo, Passo Fundo, 2012. https://doi. org/10.1590/1982-4017.140207.4013

FIORIN, J. L. O ethos do enunciador. In: MARCHEZAN, A. CORTINA, A. R. (org.). Razões e sensibilidades: a semiótica em foco. Araraquara (SP): UNESP. 2004. https://doi. org/10.18309/anp.v1i21.497

FLORES, V. do N. O primeiro momento: pessoa e não pessoa. In: Introdução à teoria enunciativa de Benveniste. São Paulo: Parábola. 2013. p. 87-125.

FREITAS, E. C. Linguagem na atividade de trabalho: éthos discursivo em editoriais de jornal interno de empresa. Desenredo, Passo Fundo, v. 6, n. 2, p. 170-197, jul./dez. 2010.

FREITAS, E. C. Práticas de linguagem na atividade de trabalho: cenografia e ethos em discursos socioprofissionais. Revista Latinoamericana de Estudos do Discurso, Colombia, v. 11, n. 2, 2011. https://doi.org/10.35956/v.15. n1.2015.p.23-40 
FREITAS, E. C.; FACIN, D. Semântica Global e os planos constitutivos do discurso. Desenredo, Passo Fundo, v. 7, n. 2 , p. 198-218, jul./dez. 2011.

JORNAL NACIONAL. Aécio Neves é entrevistado no Jornal Nacional. 2014a. Disponível em: http:/g1.globo.com/ jornal-nacional/noticia/2014/08/aecio-neves-e-entrevistadono-jornal-nacional.html. Acesso em: 08 out. 2014. https://doi. org/10.18617/liinc.v10i1.663

JORNAL NACIONAL. Dilma Roussef é entrevistada no Jornal Nacional. 2014b. Disponível em: http://g1.globo.com/ jornal-nacional/noticia/2014/08/dilma-rousseff-e-entrevistadano-jornal-nacional-.html. Acesso em: 08 out. 2014. https://doi. org/10.18617/liinc.v10i1.663

JORNAL NACIONAL. Marina Silva é entrevistada no Jornal Nacional. 2014c. Disponível em: http://g1.globo.com/ jornal-nacional/noticia/2014/08/marina-silva-e-entrevistadano-jornal-nacional.html. Acesso em: 08 out. 2014. https://doi. org/10.17058/signo.v44i79.12836

MAINGUENEAU, D. Análise de textos de comunicação. Tradução de Cecília P. de Souza-e-Silva, Décio Rocha. São Paulo: Cortez, 2002. https://doi.org/10.18309/anp.v1i12.518

MAINGUENEAU, D. (1984). Gênese dos discursos. São Paulo: Parábola Editorial, 2008a.

MAINGUENEAU, D. (2005). Ethos, cenografia, incorporação. In: AMOSSY, Ruth (Org.). Imagens de si no discurso: a construção do ethos. Tradução Dilson Ferreira da Cruz, Fabiana Komesu e Sírio Possenti. São Paulo: Contexto, 2008b. p. 69-92. https://doi.org/10.26512/les.v10i2.9291

MAINGUENEAU, D. (2006). Cenas da enunciação. São Paulo: Parábola Editorial, 2008c.

SERENA, M. G. A cenografia no discurso literário: enlaçamento enunciativo e ethos no romance Eva Luna. 2013. 109 p. Dissertação (Mestrado em Letras) - Universidade de Passo Fundo, Passo Fundo, 2013. https://doi.org/10.29289/25 94539420190000424

TEIXEIRA, M. Um olhar enunciativo sobre o discurso. In: BARBISAN, L. B.; DI FANTI, M. da G. Enunciação e discurso. São Paulo: Contexto. 2012. p.62-74.

Recebido em: 18/5/2018.

Aprovado em: 30/9/2019.

Publicado em: 21/12/2019

\section{Autor:}

IVERTON GESSÉ RiBeIRo GonÇALVES

Mestre e doutorando, Universidade de Passo Fundo, Passo Fundo, RS,

Brasil.

Orcid: https://orcid.org/0000-0003-3712-6363

E-mail: hywerthom@hotmail.com

Endereço: Av. Brasil Leste, 285 - São José

99052-900, Passo Fundo, RS, Brasil 